\title{
On the Trade Impact of Nominal Exchange Rate Volatility
}

\author{
Silvana Tenreyro*
}

April 28, 2004

\begin{abstract}
What is the effect of nominal exchange rate variability on trade? I argue that the methods conventionally used to answer this perennial question are plagued by a variety of sources of systematic bias. I propose a novel approach that simultaneously addresses all of these biases, and present new estimates from a broad sample of countries from 1970 to 1997. The answer to the question is "Zero:" Nominal exchange rate variabibily has no impact on trade flows.

Key words: Exchange rate volatility, Trade, Gravity equation, Heteroskedasticity, Poisson regression, Instrumental Variable.

JEL Codes: C21, F10,F11, F12, F15
\end{abstract}

${ }^{*}$ Federal Reserve Bank of Boston, 600 Atlantic Avenue, Boston, MA 02106-2076, USA. Fax: +1 617-9733957. E-mail: Silvana.Tenreyro@bos.frb.org. I am grateful to Francesco Caselli, Jane Little, Ken Rogoff, and Joao Santos Silva for extremely helpful comments and suggestions. Jiaying Huang provided excellent research assistance. The views in this paper are solely the responsibility of the author and should not be interpreted as reflecting the views of the Federal Reserve Bank of Boston or of the Federal Reserve System. 


\section{Introduction}

Major changes are reshaping the international monetary system. The Communist Party in China is considering the idea of floating the Chinese yuan and so are several Asian governments. ${ }^{1}$ In the same direction, although prompted by the drastic collapse of its currency board, Argentina has moved towards a (managed) float. On the other extreme, and after the recent institution of the euro, many countries in Eastern Europe are joining while others are expected to join the euro area. El Salvador and Guatemala have reinforced their peg to the dollar, and Ecuador has dollarized its economy.

These recent developments have reinvigorated the policy debate over the pros and cons of different exchange rate systems. One of the issues in the debate is the trade effect of nominal exchange rate variability. ${ }^{2}$ Proponents of fixed exchange rates have long argued that the risks associated with exchange rate variability discourage economic agents from trading across borders. Opponents have maintained that there are good instruments to hedge against this type of nominal volatility, and hence this effect should be immaterial. The question of the magnitude of the trade effect of exchange rate variability is an empirical one, and the subject of this investigation. ${ }^{3}$

The economics literature has provided at best mixed results. Most early studies, including Abrahms (1980) and Thursby and Thursby (1987), document a large negative effect of nominal variability on trade. ${ }^{4}$ Studies from the 1990s, including Frankel and Wei (1993), Eichengreen and Irwin (1995), and

\footnotetext{
${ }^{1}$ Currently, the Malaysian ringgit is pegged to the US dollar and the Hong Kong dollar is tied to the US dollar through a currency board. Other Asian countries are officially floating, but the facto, central banks have been intervening to keep their currencies fixed to the US dollar.

${ }^{2}$ Three other important issues are part of the debate: One is the relevance (or irrelevance) of monetary policy independence to dampen business cycle fluctuations. Another is the effect of exchange rate variability on financial markets. And a third issue is the ability of different regimes to stabilize inflation.

${ }^{3}$ The focus on nominal exchange rate variability (as opposed to real exchange rate variability) owes to the fact that the nominal rate is a priori the monetary instrument that policy makers can directly affect. In practice, however, nominal and real exchange rates move very closely, so, learning about the implications of nominal variability amounts to learning about the implications of real variability.

${ }^{4}$ The exception is Hooper and Kohlhagen (1978), who find no significant effects on trade volumes but a big effect on prices.
} 
Frankel (1997) report negative, albeit quantitatively small effects. ${ }^{5}$ More recent studies on the effect of currency unions and unilateral dollarizations on trade, however, document large effects. (See, for example, Rose (2000); Engel and Rose (2000), Frankel and Rose (2002), Alesina, Barro, and Tenreyro (2002); and Tenreyro and Barro (2002).) Frankel and Rose (2001) extend the analysis to currency boards, also finding significantly large effects. It could be argued that currency unions involve more than the mere elimination of exchange rate variability, although the case is less clear for currency boards. Furthermore, some critics have contended that countries that have historically been part of a currency union are too small and too poor to make generalizations about the effect of currency unions (boards) in larger countries. These interpretations and criticisms reinforce the need for a second look at the data that is not limited to this extreme type of exchange rate regime.

This paper argues that there are several estimation problems in previous studies of the impact of nominal variability (and more generally, of exchange rate regimes) on trade that cast doubt on previous answers. These studies have typically been framed in the context of the "gravity equation" model for trade. ${ }^{6}$ In its simplest form, the gravity equation states that exports from country $i$ to country $j$, denoted by $T_{i j}$, are proportional to the product of the two countries' GDPs, denoted by $Y_{i}$ and $Y_{j}$, and inversely proportional to their distance, $D_{i j}$, broadly construed to include all factors that might create trade resistance. The gravity equation is then augmented to account for the resistance $\mu_{i j}$, created by exchange rate variability. That is:

$$
T_{i j}=\alpha_{0} Y_{i}^{\alpha_{1}} Y_{j}^{\alpha_{2}} D_{i j}^{\alpha_{3}} \mu_{i j}^{\alpha_{4}} \varepsilon_{i j}
$$

\footnotetext{
${ }^{5}$ See also De Grauwe and Skudelny (2000), who focus on European trade flows, and find statistically significant negative effects. See Côté (1994) and Sekkat (1997) for recent surveys on the literature.

${ }^{6}$ For theoretical foundations of the gravity equation model, see, for example, Anderson (1979), Helpman and Krugman (1985), Bergstrand (1985), Davis (1995), Deardoff (1998), Haveman and Hummels (2001), Feenstra, Markusen, and Rose (1999), Eaton and Kortum (2001), and Anderson and van Wincoop (2003). In Appendix B I present one possible motivation for the gravity equation, based on Barro and Tenreyro (2001), which in turn builds on some of the earlier contributions.
} 
where $\varepsilon_{i j}$ is an error term, typically assumed to be statistically independent of the regressors, with $E\left(\varepsilon_{i j} \mid Y_{i}, Y_{j}, D_{i j}\right)=1$, and the $\alpha$ 's are parameters to be estimated. The standard practice consists of log-linearizing equation (1) and estimating the parameters of interest, in particular $\alpha_{4}$, by ordinary least squares (OLS) using the equation

$$
\ln \left(T_{i j}\right)=\ln \left(\alpha_{0}\right)+\alpha_{1} \ln \left(Y_{i}\right)+\alpha_{2} \ln \left(Y_{j}\right)+\alpha_{3} \ln \left(D_{i j}\right)+\alpha_{4} \ln \left(\mu_{i j}\right)+\ln \left(\varepsilon_{i j}\right) .
$$

There are at least four problems with this procedure. First, it is very unlikely that the variance of $\varepsilon_{i j}$ in (1) will be independent of the countries' GDPs and of the various measures of distance between them. In other words, the error term $\varepsilon_{i j}$ is generally heteroskedastic. Since the expected value of the logarithm of a random variable depends both on its mean and on higher-order moments of its distribution, whenever the variance of the error term $\varepsilon_{i j}$ in equation (1) depends on $Y_{i}, Y_{j}, \mu_{i j}$, or $D_{i j}$, the expected value of $\ln \left(\varepsilon_{i j}\right)$ will also depend on the regressors, violating the condition for consistency of OLS. This is simply the result of Jensen's inequality: $E(\ln \varepsilon) \neq \ln E(\varepsilon)$, and $E(\ln \varepsilon)$ depends on the distribution of $\varepsilon$. In particular, if $\varepsilon$ is $\log$-normal, $E(\ln \varepsilon)$ is a function of the mean and variance of $\varepsilon$. Santos Silva and Tenreyro (2003) find this to be a serious source of bias in practical applications of the gravity equation.

Second, pairs of countries for which bilateral trade is zero have to be dropped out of the sample, as a result of the logarithmic transformation. In a typical data set, this leads to the loss of over 30 percent of the data points. This massive sample selection can cause additional biases in the estimation.

Third, with a few exceptions, previous studies assume that exchange rate variability is exogenous to the level of trade. Standard endogeneity problems, however, are likely to confound the estimates. For example, two countries willing to increase their bilateral trade through lower exchange rate volatility 
might undertake additional steps to foster integration (such as lowering regulatory barriers, harmonizing standards of production, and so on). To the extent that these steps cannot be measured in the data, simple OLS estimates will tend to produce a bias.

Fourth, there is significant measurement error in official statistics on nominal exchange rates, and hence in the corresponding measures of variability. ${ }^{7}$

In this paper, I argue that partial corrections of the different biases can lead to misleading answers, and that all biases should be tackled simultaneously. I hence propose an approach to estimation that simultaneously addresses all of these problems.

In a nutshell, my approach is to deal with the problems generated by heteroskedsasticity and zerotrade observations by estimating the trade-volatility relation in levels, instead of logs, as is usually done. More specifically, I use a pseudo-maximum likelihood (PML) technique whose efficiency and robustness in the context of gravity equations has been established by Santos Silva and Tenreyro (2003). To deal with the endogeneity and the measurement error of the exchange rate variability I then develop an instrumental-variable (IV) version of the PML estimator.

The idea behind the IV is as follows. For a variety of reasons (which I review below) many countries find it useful to peg their currency to that of a large, and stable "anchor" country (e.g., the US, France). Hence, two countries that have chosen to peg to the same anchor will experience low bilateral exchange rate variability. I turn this observation into an identification strategy by first estimating the probability that two countries will be pegged to the same anchor, and then using this probability as an instrument for their bilateral exchange rate volatility. Crucially, I estimate this "propensity to share a common anchor" by using exclusively information on the relationship between the anchor country and each individual "client" country, so that my instrument only captures reasons for pegging to the anchor

\footnotetext{
${ }^{7}$ See the discussion on reporting errors by Reinhart and Rogoff (2002).
} 
country other than the desire to increase bilateral trade among the two clients. In Section 3.2 I elaborate further on this point.

Using a broad sample of countries from 1970 to 1997, and after accounting for all sources of bias, the analysis leads to the conclusion that exchange rate variability has no significant impact on trade. The absence of any significant effect goes against the view that stabilization of exchange rates is necessary to foster international trade. As later explained, this result can be rationalized by the fact that exchange rate fluctuations not only create uncertainty or risks, which tend to discourage trade across borders, but they also create profitable opportunities. This finding might also suggest that the availability of forward contracts, currency options, and other alternatives for diversification provide sufficient hedging to reduce the potential drawbacks of exchange rate variability on trade. The absence of effect is also consistent with the model proposed by Bacchetta and van Wincoop (2000), who show that in a general equilibrium context, exchange rate stability may have no impact on trade.

The remainder of the paper is organized as follows. Section 2 comments on previous attempts at addressing the biases highlighted in the paper. Section 3 discusses in further detail the problems raised by log-linearization in the presence of heterogeneity, the exclusion of zeroes, and the endogeneity of the regressors. It then presents my PML-IV method to address the various econometric problems. Section 4 studies the effect of exchange rate variability on trade, using different methodologies. Section 5 contains concluding remarks.

\section{Related literature}

Of the substantial literature that has been devoted to assess the impact of exchange rate volatility on trade, a few papers bear a particularly close relationship with the present one. 
The IV approach to assessing the effect of exchange-rate variability was pioneered by Frankel and Wei (1993), who used the variability in relative quantities of money as an instrument for nominal exchange rate volatility. One objection to this IV is that movements in money demand and supply are driven by factors that are also likely to affect trade flows directly. Another objection is that they estimate the equation in log form, and therefore their estimates suffer from the biases associated with heteroskedasticity and selectivity.

Tenreyro and Barro (2003) and Alesina, Barro, and Tenreyro (2002) use a "triangular" IV similar in spirit to the one in this paper, for the narrower question of the effect of currency unions (as opposed to the general question of exchange rate variability, which is the focus here). It is clear from the results of this paper that the findings from currency unions do not generalize to other regimes with low variability. Furthermore, these authors also looked at a log specification.

More recently, Broda and Romalis (2004) estimate the effect of exchange rate variability on the composition of trade and then back out the effect of exchange rate variability on total trade. They make two assumptions. First, exchange rate variability is exogenous to the composition of trade flows, so that its effect on the relative importance of trade in homogeneous goods versus differentiated goods can be estimated by OLS. Second, they assume that volatility does not affect homogeneous-goods trade, which allows them to back out the effect on total trade from the effect on the composition. While this is an ingenious approach, the two assumptions on which it rests seem potentially debatable. In addition, their estimates are also based on the log-linear form.

There have also been previous estimates of the gravity equation in levels. Notably, Frankel and Wei (1993) use non-linear least squares (NLS) estimation. Santos Silva and Tenreyro (2003), however, show that NLS can be highly inefficient, based on a series of Monte Carlo simulations. These authors also present application of the PML estimator in the context of gravity equations, but do not include 
exchange rate volatility nor do they instrument the regressions.

Next section discusses the biases in detail, the drawbacks of partial corrections, and an alternative approach to the problem.

\section{Estimation issues}

\subsection{Sources of bias}

As mentioned in the introduction, there are various potential sources of bias in standard estimations of the effect of nominal exchange rate variability. The first one comes from log-linearizing the gravity equation, given the heteroskedastic nature of trade data. (In fact, any non-linear transformation of the dependent variable in the presence of heteroskedasticity will generally lead to inconsistent estimators.)

It may appear that one could simply assume in equation (1) that $E \ln \left(\varepsilon_{i j}\right)=0$, as has been implicitly done in previous studies. This, however, would still not solve the problem if $\ln \left(\varepsilon_{i j}\right)$ is heteroskedatic. $^{8}$ To see why, note that, ultimately, we are interested in the elasticity of the expected value of trade, $E\left(T_{i j}\right)$, with respect to the variability term, $\mu_{i j}$; that is, $\frac{\partial E\left(T_{i j}\right)}{\partial \mu_{i j}} \cdot \frac{\mu_{i j}}{E\left(T_{i j}\right)}$. If the variance of $\ln \left(\varepsilon_{i j}\right)$ depends on the regressors, then, by Jensen's inequality, $E\left(\varepsilon_{i j} \mid Y_{i}, Y_{j}, D_{i j}\right)=E\left(\exp \left(\ln \varepsilon_{i j}\right) \mid Y_{i}, Y_{j}, D_{i j}\right)$ will in general be a function of the regressors. The variability-elasticity of trade flows will be then given by

$$
\frac{\partial E\left(T_{i j}\right)}{\partial \mu_{i j}} \frac{\mu_{i j}}{E\left(T_{i j}\right)}=\alpha_{4}+\frac{\partial E\left(\varepsilon_{i j} \mid Y_{i}, Y_{j}, D_{i j}\right)}{\partial \mu_{i j}} \frac{\mu_{i j}}{E\left(T_{i j}\right)} .
$$

which is different from $\alpha_{4}$. So, while OLS consistently estimates $\alpha_{4}$ in this case, the estimated coefficient will be a biased estimate of the true elasticity $\frac{\partial E\left(T_{i j}\right)}{\partial \mu_{i j}} \frac{\mu_{i j}}{E\left(T_{i j}\right)}$. The extent of the bias is given by

\footnotetext{
${ }^{8}$ Trade economists know that this is indeed the case in any bilateral trade regressions: Homoskedasticity is always rejected in the log specification and in the level specification.
} 
$\frac{\partial E\left(\varepsilon_{i j} \mid Y_{i}, Y_{j}, D_{i j}\right)}{\partial \mu_{i j}} \frac{\mu_{i j}}{E\left(T_{i j}\right)}$.

Hence, even if $E \ln \left(\varepsilon_{i j}\right)=0$, when $\ln \left(\varepsilon_{i j}\right)$ is heteroskedastic we cannot retrieve the true elasticity of expected trade with respect to variability using OLS, unless we know the distribution of $\varepsilon_{i j}$.

The second source of bias stems from the existence of observations with zero value for trade. While these zero valued observations pose no problem for the estimation of gravity equations in their multiplicative form, they create an additional problem for the use of the log-linear form of the gravity equation. Several methods have been developed to deal with this problem (see Frankel (1997) for a description of the various procedures). The approach followed by most empirical studies is simply to drop the pairs with zero trade from the data set and estimate the log-linear form by OLS. This truncation makes the OLS estimator of $\beta$ inconsistent, even in the absence of heteroskedasticity. Frankel and Wei (1993) present NLS estimates to check the robustness of the results with respect to the inclusion of zeroes. However, these authors estimate the model only for variables other than exchange rate variability, and hence one cannot assess from their reports to what extent the inclusion of zeroes affects the estimates of the effect of nominal exchange rate variability on trade. In any case, as argued in a previous footnote, the NLS estimator, while consistent, tend to be highly inefficient, and the PML estimator should be preferred.

The third source of bias relates to the potential endogeneity of exchange rate variability, that is, $E\left(v_{i j} \mid x\right) \neq 0$. The underlying assumption in most studies is that exchange rate regimes, and, therefore, the implied exchange rate variability, are randomly assigned among countries. In practice, however, unmeasured characteristics might create spurious links between exchange rate variability and trade. Two countries willing to lower their exchange rate volatility might also be prone to foster integration and trade through other channels, for example, by reducing or eliminating regulatory barriers or by encouraging the harmonization of product standards to enhance competition and exchange. These 
unmeasured characteristics might lead to positive biases in simple estimations of the gravity equation. The bias may also go in the other direction, as in the model by Barro and Tenreyro (2001). In this model, higher levels of monopoly distortion imply higher markups, which tend to deter trade. At the same time, higher markups lead to higher inflation rates under discretion and therefore increase the need for external commitments (such as currency boards, currency unions, or other strong pegs) in order to reduce inflation. This mechanism may, therefore, lead to a positive correlation between exchange rate variability and trade.

A fourth potential source of bias is measurement error. As Reinhart and Rogoff (2002) demonstrate, official statistics on exchange rates are particularly contaminated by reporting errors. ${ }^{9}$ And, therefore, so is the measure of variability used in empirical studies. In general, measurement error will lead to inconsistency of the estimators, which is yet an additional reason to prefer the use of IV. However, as it will soon be argued, the IV should be applied to the multiplicative form of the gravity equation, since the logarithmic version can lead to further biases.

\subsection{Correcting the Biases}

\subsubsection{The PML-IV methodology}

To develop the PML-IV methodology, I build on Santos-Silva and Tenreyro (2003), who propose a Poisson PML estimator that allows for consistent estimation of $\frac{\partial E\left(T_{i j}\right)}{\partial \mu_{i j}} \frac{\mu_{i j}}{E\left(T_{i j}\right)}$ in the absence of endogeneity. To simplify notation, I write the gravity equation throughout the paper in its exponential

\footnotetext{
${ }^{9}$ Reinhart and Rogoff (2002) find big disparities between what countries report (basically the exchange rate regime of the country) and what they actually do.
} 
form: ${ }^{10,11}$

$$
T_{i j}=\exp \left(x_{i j} \beta\right)+v_{i j}
$$

where vector $x_{i j}$ includes, among other variables, (the log of) the countries' per capita GDPs, population size, geographical distance between them, and other dimensions of "distance," proxied by dummy variables indicating whether the countries share a common border, the same language, or a common colonial history. $x_{i j}$ also includes the term $\ln \left(\mu_{i j}\right)$, to reflect the impact of exchange rate variability. To account for "remoteness" or "multilateral resistance," $x_{i j}$ includes a set of country-specific dummies, $c_{i} \cdot{ }^{12}$

In the absence of endogeneity, that is, if $E\left(v_{i j} \mid x\right)=0$, the Poisson PML estimator is defined by

$$
\tilde{\beta}=\underset{b}{\arg \max } \sum_{i, j}^{n}\left\{T_{i j} \cdot\left(x_{i j} b\right)-\exp \left(x_{i j} b\right)\right\},
$$

\footnotetext{
${ }^{10}$ Note that whether the error term $v_{i j}$ enters additively or multiplicatively is irrelevant, since both representations are observationally equivalent. For further discussion on this, see Santos Silva and Tenreyro (2003) and the references therein. The subscripts for time have been omitted for simplicity.

${ }^{11}$ In the text, I refer, indistinctly, to the gravity equation in its exponential or multiplicative form, to indicate that trade is expressed in levels (as opposed to logs). Note that the general form of the gravity equation is:

$$
T_{i j}=\prod_{k=1}^{\bar{L}} w_{k, i j}^{\alpha_{k}} \prod_{k=\bar{L}+1}^{\bar{K}} \exp \left(w_{k, i j} \alpha_{k}\right)+v_{i j}
$$

where the $\bar{L}$ regressors $w_{k}, k=1, \ldots \bar{L}$, are strictly positive (income, population, etc.) and hence, can be expressed as $w_{k}=\exp \left(\ln w_{k}\right)$. The remaining $\bar{K}-\bar{L}$ regressors, $w_{k}, k=\bar{L}+1, \ldots \bar{K}$, are dummy variables that enter the gravity equation exponentially. Renaming variables as $x_{k}=\ln w_{k}$ if $k=1, \ldots \bar{L}$, and $x_{k}=w_{k}$ for $k=\bar{L}+1, \ldots \bar{K}$, leads to expression (3), where $x_{i j}$ is the $\bar{K}$-dimensional vector corresponding to observation $(i, j)$.

${ }^{12}$ To illustrate the role of remoteness or relative distance, consider two pairs of countries, $(i, j)$ and $(k, l)$, and assume that the distance between the countries in each pair is the same $D_{i j}=D_{k l}$; however, $i$ and $j$ are closer to other countries. In this case, the more remote pairs of countries, $k$ and $l$, will tend to trade more between each other because they do not have alternative trading partners (see Deardoff (1998)). See also Anderson and van Wincoop (2003) for a formulation of the more general concept of "multilateral resistance," and Rose and van Wincoop (2000) for a related empirical implementation.
} 
which is equivalent to solving the following set of first-order conditions:

$$
\sum_{i=1}^{n}\left[T_{i j}-\exp \left(x_{i j} \tilde{\beta}\right)\right] x_{i j}=0
$$

The form of (4) makes clear that all that is needed for this estimator to be consistent is for the conditional mean to be correctly specified, that is, $E\left[T_{i j} \mid x_{i j}\right]=\exp \left(x_{i j} \beta\right) .{ }^{13}$ Note that, terminology aside, this is simply a Generalized Method of Moments (GMM) estimator that solves the moment conditions in equation (4). ${ }^{14}$

Turning now to the IV estimation, suppose that one or more of the regressors are no longer exogenous, that is, $E\left(u_{i j} \mid x_{i j}\right) \neq 0$. If $z_{i j}$ is a set of instruments such that $E\left(u_{i j} \mid z_{i j}\right)=0$, this setup leads to the following moment conditions:

$$
\sum_{i=1}^{n}\left[T_{i j}-\exp \left(x_{i j} \bar{\beta}\right)\right] z_{i j}=0 .
$$

Note that this moment (or orthogonality) condition has the same form as that stated in equation (4), and the condition $E\left(u_{i j} \mid z_{i j}\right)=0$ ensures the consistency of the estimator. ${ }^{15}$ The vector $z_{i j}$ includes

\footnotetext{
${ }^{13}$ In the empirical estimation, a correction for heteroskedasticity (and correlation of errors) is allowed for.

${ }^{14} \mathrm{An}$ alternative would be to use a simple non-linear least square estimator (NLS). The NLS estimator of $\beta$ is defined by

$$
\hat{\beta}=\underset{b}{\arg \min } \sum_{i, j}^{n}\left[T_{i j}-\exp \left(x_{i j} b\right)\right]^{2},
$$

which implies the following set of first order conditions:

$$
\sum_{i, j}^{n}\left[T_{i j}-\exp \left(x_{i j} \hat{\beta}\right)\right] x_{i j} \exp \left(x_{i j} \hat{\beta}\right)=0 .
$$

These equations give more weight to observations where $\exp \left(x_{i} \hat{\beta}\right)$ is large. Note, however, that these are generally also the observations with larger variance, which implies that NLS gives more weight to noisier observations. Thus, this estimator may be very inefficient, depending heavily on a small number of observations. Santos Silva and Tenreyro (2003) perform a series of Monte Carlo experiments in gravity equations, which reveal that the PML approach is significantly more efficient than NLS in trade data models.

${ }^{15}$ See Windmeijer and Santos Silva (1997) for further discussion.
} 
all the regressors in the gravity equation (except for the measure of nominal exchange rate variability, which is endogenous) and the additional instrument that, as mentioned before, exploits the relation between each country in a given pair with third anchor-countries.

It is important to point out that an IV that is appropriate for the equation in levels is not necessarily appropriate for the $\log$ specification. To see this, observe that equation (3) can be written as $T_{i j}=$ $\exp \left(x_{i j} \beta\right)\left(1+\xi_{i j}\right)$, where $\xi_{i j}=u_{i j} / \exp \left(x_{i j} \beta\right)$. If $T_{i j}$ is strictly positive, the log-linear version will be given by $\ln T_{i j}=x_{i j} \beta+\eta_{i j}$, with $\eta_{i j}=\ln \left(1+\xi_{i j}\right)$. If $u_{i j}$ in (3) is heteroskedastic,e $z_{i j}$ will generally fail to satisfy the condition $E\left[\eta_{i j} \mid z_{i j}\right]=E\left[\ln \left(1+\frac{u_{i j}}{\exp \left(x_{i j} \beta\right)} \mid z_{i j}\right)\right]=0$, and hence IV estimates in the $\log$ form will generally be inconsistent. ${ }^{16}$ (Needless to repeat, the requirement that $T_{i j}$ be strictly positive already conflicts with the facts.) Hence, the IV approach has to be applied to the multiplicative version of the gravity equation for it to produce a consistent estimator, which makes a strong case for the use of the PML-IV estimator

\subsubsection{The propensity to anchor the currency as instrument}

Alesina and Barro (2002) provide a formal model for the anchor-client relationship in the context of the currency-union decision, which can be generalized to the choice of nominal anchors. The model shows that countries with lack of internal discipline for monetary policy (as revealed by a history of high and variable inflation) stand to gain more from pegging their currencies, provided that the anchor country is able to commit to sound monetary policy. This commitment is best protected when the anchor is

\footnotetext{
${ }^{16}$ In general, $E\left[\ln \left(1+\frac{u_{i j}}{\exp \left(x_{i j} \beta\right)}\right) \mid z_{i j}\right]$ is different from zero (and, it typically will be a function of the regressors, $x_{i j}$ ). If $u_{i j}$ is heteroskedastic, that is, if its variance is a function of the regressors $x_{i j}$, since the expected value of the non-linear transformation $\ln \left(1+\frac{u_{i j}}{\exp \left(x_{i j} \beta\right)}\right)$ depends on higher-order moments of the distribution of $u_{i j}$, then, $E\left[\ln \left(1+\frac{u_{i j}}{\exp \left(x_{i j} \beta\right)}\right) \mid z_{i j}\right]$ generally will be a function of $x_{i j}$, violating the condition for consistency. Only under very special assumptions on the form of heteroskedasticity will the denominator $\exp \left(x_{i j} \beta\right)$ in $\ln \left(1+\frac{u_{i j}}{\exp \left(x_{i j} \beta\right)}\right) \operatorname{cancel} \operatorname{this}$ effect.
} 
large and the client small (otherwise, the anchor may find it advantageous to change the conduct of monetary policy). In addition, the model shows that, under reasonable assumptions, client countries benefit more from choosing an anchor with which they would naturally trade more, that is, an anchor with which trading costs - other than the ones associated to high exchange rate variability- are small. These features of the relation between clients and anchors are used to guide the instrumentation.

To construct the instrument, I use a logit analysis for all country pairings from 1960 to 1997 with five potential anchors that fit the theoretical characterization of Alesina and Barro (2002) and whose currencies have served as "reference" for other countries, according to Reinhart and Rogoff's classification. ${ }^{17,18}$. Two important characteristics here are country size (GDP) and a record of low and stable inflation. The group of anchors in my analysis includes France, Germany, South Africa, the United Kingdom, and the United States. I consider effectively anchored currencies those characterized by the following regimes: No-legal-tender (including currency unions), currency boards, pegs, and bands. By exclusion, freely floating, managed floats, moving bands, crawling bands, and crawling pegs are not considered nominally anchored, since they allow for significant departures from initial nominal parities. The logit regressions include various measures of distance between clients and anchors (to proxy for trading costs) and the sizes of potential clients and anchors.

To make the methodology more transparent, consider a potential client country $i$, deciding whether or not to anchor its currency to one of the five reference currencies $k(k=1,2, \ldots, 5)$. The logit regression determines the estimated probability $p(i, k, t)$ that client $i$ anchors its currency to that of anchor $k$ at

\footnotetext{
${ }^{17}$ The Australian dollar has played a reference role for some of the Pacific islands, but the islands are not included in this study; the same note goes for the Indian rupee, which has served as an anchor for Bhutan, but Bhutan is not in the sample. See Table A1 in the Appendix for a list of the countries included in this study.

${ }^{18}$ Note also that in the first year of the analysis, the anchors were themselves pegs, following the gold standard. Still then, one can identify, following Reinhart and Rogoff (2002) what countries were serving as anchors for the rest. To give an example, the ex-French colonies in Africa are classiffied by Reinhart and Rogoff as tracking the French franc, rather than independently following some or all of the other anchors. As a robustness check, I repeated the excercises eliminating the first years of the sample, (1970-1973) and the main findings remained unaltered.
} 
time $t$. If two clients, say $i$ and $j$, anchor their currencies to the same anchor independently, then the joint probability that countries $i$ and $j$ have the same nominal anchor $k$ at time $t$ is given by:

$$
P^{k}(i, j, t)=p(i, k, t) \cdot p(j, k, t)
$$

The probability $P^{k}(i, j, t)$ will be high if anchor $k$ is attractive for both countries. The joint probability that at time $t$, countries $i$ and $j$ use the same anchor (among the five candidates considered in this analysis) is given by the sum of the joint probabilities over the support of potential anchors:

$$
P(i, j, t)=\sum_{k=1}^{5} P^{k}(i, j, t)=\sum_{k=1}^{5} p(i, k, t) \cdot p(j, k, t) .
$$

The variable $P(i, j, t)$ can be used as an instrument for exchange rate variability in the regressions of bilateral trade. The key point is that the propensity to share a common anchor exclusively uses information on the relationship between the anchor country and each individual client country, so that the instrument only captures reasons for pegging to the anchor country other than the desire to increase bilateral trade among the two clients.

Bilateral variables involving third countries affect the likelihood that the clients $i$ and $j$ share a common reference currency and thereby influence bilateral trade between $i$ and $j$ through that channel. The assumption requires that these factors not influence the bilateral trade between $i$ and $j$ through other channels.

A question one might ask is to what extent the bilateral variables between each client and the third anchor-countries convey new information beyond the bilateral variables between two potential clients. More concretely, consider whether the joint probability of pegging to a common anchor's currency, 
$P(i, j, t)$, adds information, given that the regressions control separately for the bilateral characteristics of the two clients, $i$ and $j$. The key point is that the bilateral relations are not transitive. As a first example, the geographical distance from client $i$ to anchor $k$ and that from client $j$ to anchor $k$ do not pin down the distance between $i$ and $j$. This distance depends on the location of the countries. Similarly, because the language variable recognizes that countries can speak more than one main language, the relation is again non-transitive. For example, if anchor $k$ speaks only French and country $i$ speaks English and French, $k$ and $i$ speak the same language. If another country, $j$, speaks only English, it does not speak the same language as $k$. Nevertheless, $i$ and $j$ speak the same language.

\section{The effect of variability on trade}

This section presents the estimated impact of exchange rate variability using different methods. The analysis considers 104 countries, which are listed in Table A1 in the Appendix.

The regressions use annual data from 1970 to 1997 for all pairs of countries. ${ }^{19}$ Data on bilateral exports come from Feenstra, Lipsey, and Bowen (1997). ${ }^{20}$ Data on real per capita GDP and population come from the World Bank's World Development Indicators (2002).

Information on geographical area, geographical location, and dummies indicating contiguity, common language, colonial ties, and access to water come from the CIA's World Factbook. Bilateral distance is computed using the great circle distance algorithm provided by Andrew Gray (2001). Finally, information on free-trade agreements comes from Frankel (1997), complemented with data from

\footnotetext{
${ }^{19}$ Note that most studies on exchange rate variability have focused on only a few countries and/or a few years, whereas the present study encompasses a broad sample of countries over 28 years. The sample, hence, consists of 299,936 $(=104 \times 103 \times 28)$ year-pair observations. There are, however, missing observations for some countries in early years, which reduces the total number of observations to 254,942 .

${ }^{20}$ Bilateral trade flows, expressed in current U.S. dollars, are converted into constant 1995 U.S. dollars using the U.S. CPI index. This transformation, however, does not affect the estimated impact of variability on trade, as all regressions include time-fixed effects.
} 
the World Trade Organization. Table A2 in the Appendix provides a list of the free-trade agreements considered in the study. Data on monthly exchange rates come from the IMF's International Financial Statistics, provided by Haver Analytics. Exchange rate variability between countries $i$ and $j$ in year $t$, denoted by $\delta_{i j t}$, is measured as the standard deviation of the first difference of (the logarithm of) the monthly exchange rate between the two countries, $e_{i j t, m}$ :

$$
\delta_{i j t}=S t d . D e v \cdot\left[\ln \left(e_{i j t, m}\right)-\ln \left(e_{i j t, m-1}\right)\right], \quad m=1 \ldots 12 .
$$

The trade resistance caused by exchange rate variability is then measured as $\mu_{i j}=1+\delta_{i j}$. When $\delta_{i j}=0$, that is, when there is no exchange-rate variability, $\mu_{i j}=1$, and there is no trade resistance (see equation (1)).

Table A3 in the Appendix provides a description of the variables and displays the summary statistics. The first two columns show, respectively, the means and standard deviations for all country-pairs for which data are available during the period. The third and fourth columns present the means and deviations of the subsample resulting from excluding the five anchor countries, which will be relevant for the IV estimation. As could be expected, the subsample that excludes the main anchors exhibits lower average levels of trade flows and GDPs per capita, as well as a lower unconditional probability of being part of a free-trade agreement.

\subsection{Linear vs. non-linear estimation}

Table 1 presents the benchmark estimation outcomes using OLS and PML. The regressions include all the controls typically present in gravity equation models. All regressions include year effects and allow for clustering of the error terms over time for country pairs. 
Table 1. Exchange Rate Volatility and Trade

\begin{tabular}{|c|c|c|c|c|c|c|}
\hline & \multicolumn{4}{|c|}{ Sample: Trade $>0$} & \multicolumn{2}{|c|}{ Sample: All pairs } \\
\hline & \multicolumn{6}{|c|}{ Dependent Variable: } \\
\hline & \multicolumn{2}{|c|}{ Log of Trade } & \multicolumn{2}{|c|}{ Trade } & \multicolumn{2}{|c|}{ Trade } \\
\hline & OLS & OLS-FE & PML & PML-FE & PML & PML-FE \\
\hline $\log$ of $(1+\delta)$ & $\begin{array}{l}-0.856^{* *} \\
(0.116)\end{array}$ & $\begin{array}{l}-0.468^{* *} \\
(0.070)\end{array}$ & $\begin{array}{l}-2.416^{* *} \\
(0.551)\end{array}$ & $\begin{array}{l}-0.851^{* *} \\
(0.185)\end{array}$ & $\begin{array}{l}-2.429^{* *} \\
(0.553)\end{array}$ & $\begin{array}{l}-0.886^{* *} \\
(0.189)\end{array}$ \\
\hline Log of distance & $\begin{array}{l}-1.044^{* *} \\
(0.029)\end{array}$ & $\begin{array}{l}-1.196^{* *} \\
(0.032)\end{array}$ & $\begin{array}{l}-0.596^{* *} \\
(0.048)\end{array}$ & $\begin{array}{l}-0.801^{* *} \\
(0.049)\end{array}$ & $\begin{array}{l}-0.601^{* *} \\
(0.049)\end{array}$ & $\begin{array}{l}-0.796^{* *} \\
(0.049)\end{array}$ \\
\hline Contiguity dummy & $\begin{array}{l}0.601^{* *} \\
(0.149)\end{array}$ & $\begin{array}{l}0.382^{*} \\
(0.154)\end{array}$ & $\begin{array}{l}0.371^{*} \\
(0.156)\end{array}$ & $\begin{array}{l}0.314^{* *} \\
(0.101)\end{array}$ & $\begin{array}{l}0.363^{*} \\
(0.156)\end{array}$ & $\begin{array}{l}0.313^{* *} \\
(0.102)\end{array}$ \\
\hline $\begin{array}{l}\text { Common-language } \\
\text { dummy }\end{array}$ & $\begin{array}{l}0.821^{* *} \\
(0.081)\end{array}$ & $\begin{array}{l}0.344^{* *} \\
(0.073)\end{array}$ & $\begin{array}{l}0.680 * * \\
(0.146)\end{array}$ & $\begin{array}{l}0.362^{* *} \\
(0.094)\end{array}$ & $\begin{array}{l}0.679^{* *} \\
(0.147)\end{array}$ & $\begin{array}{l}0.355^{* *} \\
(0.096)\end{array}$ \\
\hline $\begin{array}{l}\text { Colonial-tie } \\
\text { dummy }\end{array}$ & $\begin{array}{l}0.237^{* *} \\
(0.088)\end{array}$ & $\begin{array}{l}0.627^{* *} \\
(0.077)\end{array}$ & $\begin{array}{l}0.325 \\
(0.219)\end{array}$ & $\begin{array}{l}0.178 \\
(0.146)\end{array}$ & $\begin{array}{l}0.334 \\
(0.218)\end{array}$ & $\begin{array}{l}0.192 \\
(0.151)\end{array}$ \\
\hline $\begin{array}{l}\text { Free-trade } \\
\text { agreement dummy }\end{array}$ & $\begin{array}{l}-0.292^{* *} \\
(0.095)\end{array}$ & $\begin{array}{l}-0.589^{* *} \\
(0.130)\end{array}$ & $\begin{array}{l}-0.011 \\
(0.093)\end{array}$ & $\begin{array}{l}0.299^{* *} \\
(0.078)\end{array}$ & $\begin{array}{l}-0.017 \\
(0.093)\end{array}$ & $\begin{array}{l}0.294^{* *} \\
(0.079)\end{array}$ \\
\hline Log of importer's & $0.950^{* *}$ & $1.258^{* *}$ & $0.766^{* *}$ & $1.178^{* *}$ & $0.778^{* *}$ & $1.209^{* *}$ \\
\hline GDP per capita & $(0.011)$ & $(0.041)$ & $(0.032)$ & $(0.067)$ & $(0.031)$ & $(0.069)$ \\
\hline Log of exporter's & $1.141^{* *}$ & $1.430^{* *}$ & $0.796^{* *}$ & $1.206^{* *}$ & $0.809^{* *}$ & $1.240^{* *}$ \\
\hline GDP per capita & $(0.011)$ & $(0.041)$ & $(0.035)$ & $(0.070)$ & $(0.034)$ & $(0.071)$ \\
\hline $\begin{array}{l}\text { Log of importer's } \\
\text { population }\end{array}$ & $\begin{array}{l}0.934^{* *} \\
(0.014)\end{array}$ & $\begin{array}{l}0.929 * * \\
(0.084)\end{array}$ & $\begin{array}{l}0.772^{* *} \\
(0.030)\end{array}$ & $\begin{array}{l}0.040 \\
(0.119)\end{array}$ & $\begin{array}{l}0.778^{* *} \\
(0.030)\end{array}$ & $\begin{array}{l}0.050 \\
(0.114)\end{array}$ \\
\hline $\begin{array}{l}\text { Log of exporter's } \\
\text { population }\end{array}$ & $\begin{array}{l}1.030^{* *} \\
(0.015)\end{array}$ & $\begin{array}{l}1.039^{* *} \\
(0.084)\end{array}$ & $\begin{array}{l}0.778^{* *} \\
(0.044)\end{array}$ & $\begin{array}{l}0.042 \\
(0.118)\end{array}$ & $\begin{array}{l}0.786^{* *} \\
(0.043)\end{array}$ & $\begin{array}{l}0.054 \\
(0.114)\end{array}$ \\
\hline $\begin{array}{l}\text { Log of importer's } \\
\text { geographical area }\end{array}$ & $\begin{array}{l}-0.106^{* *} \\
(0.010)\end{array}$ & & $\begin{array}{l}-0.030 \\
(0.030)\end{array}$ & & $\begin{array}{l}-0.030 \\
(0.030)\end{array}$ & \\
\hline $\begin{array}{l}\text { Log of exporter's } \\
\text { geographical area }\end{array}$ & $\begin{array}{l}-0.074^{* *} \\
(0.011)\end{array}$ & & $\begin{array}{l}-0.043 \\
(0.037)\end{array}$ & & $\begin{array}{l}-0.044 \\
(0.037)\end{array}$ & \\
\hline Landlocked & $-0.454^{* *}$ & & $-0.766^{* *}$ & & $-0.773^{* *}$ & \\
\hline -importer dummy & $(0.050)$ & & $(0.123)$ & & $(0.123)$ & \\
\hline $\begin{array}{l}\text { Landlocked } \\
\text {-exporter dummy }\end{array}$ & $\begin{array}{l}-0.040 \\
(0.054)\end{array}$ & & $\begin{array}{l}-0.981^{* *} \\
(0.144)\end{array}$ & & $\begin{array}{l}-0.988^{* *} \\
(0.144)\end{array}$ & \\
\hline Year effects & Yes & Yes & Yes & Yes & Yes & Yes \\
\hline Country-fixed effects & No & Yes & No & Yes & No & Yes \\
\hline Observations & 163,928 & 163,928 & 163,928 & 163,928 & 254,942 & 254,942 \\
\hline R-squared & 0.68 & 0.73 & & & & \\
\hline
\end{tabular}

Note: The equations use annual data from 1970 to 1997 and allow for clustering of the error terms over time for country pairs. In OLS regressions the gravity equation is estimated in its log form. In PML, it is estimated in its multiplicative form. Results for the restricted sample (with positive trade) and the whole sample are reported. Country effects refer to each member of the pair (not to a country pair). Clustered standard errors are in parentheses.

* significant at $5 \%$; $* *$ significant at $1 \%$. 
The first two columns report OLS estimates using the logarithm of trade as the dependent variable.

As noted before, these regressions leave out pairs of countries with zero bilateral exports (only 163, 928 country pairs, or 64 percent of the sample, exhibit positive export flows). The second column includes country-fixed effects (and hence, time-invariant country-specific variables are dropped). ${ }^{21}$ The third and fourth columns report PML estimates restricting the sample to positive-trade pairs, in order to compare the results to those obtained with OLS. And finally, the fifth and sixth columns show the PML results for the whole sample. The first point to notice is that PML-estimated coefficients are remarkably similar using both the whole sample and the positive-trade subsample. However, most coefficients differ - often significantly - from those generated by OLS. This suggests that, in this case, heteroskedasticity can distort results in a material way, whereas truncation, as long as the model is estimated non-linearly, leads to no significant bias. ${ }^{22}$

The main findings for the control variables are the following. PML and OLS predict significantly different coefficients on (the logs of) populations and per capita GDPs. OLS significantly exaggerates the roles of geographical proximity and colonial links. Also, and against intuition, OLS estimates suggest that free-trade agreements are negatively related to trade. ${ }^{23}$ In contrast, PML indicates a significant and positive relationship: Trade between countries that share a free-trade agreement is, on average, 30 percent larger than trade between countries without a free-trade agreement. ${ }^{24}$ (Notice that controlling for country-fixed effects implicitly takes into account the possibility that free-trade

\footnotetext{
${ }^{21}$ As noted by Anderson and van Wincoop (2003) and Rose and van Wincoop (2000), including country-fixed effects is extremely important in trade regressions, for they allow one to instrument the idea of "multilateral resistance." I present the results without fixed effects in this table simply to illustrate the difference in estimates coming from their exclusion. However, the analysis henceforth will focus on regressions that control for country-fixed effects.

${ }^{22}$ The reason why truncation seems to have little effect in this case is that observations with zero trade correspond to pairs for which the estimated value of trade is close to zero. Therefore, the corresponding residuals are also close to zero, and their elimination from the sample, when the equations are estimated in their non-linear form has little effect. See Santos Silva and Tenreyro (2003) for further discussion.

${ }^{23}$ This is not an unusual result in log-linearized regressions. For example, Frankel (1997) finds that over many years the European community has had a significantly negative effect on the bilateral trade flows of its members (see Table 6.4, p. 136, and Table 6.5a, p. 141 in Frankel (1997)).

${ }^{24}$ The formula to compute this effect is $\left(e^{b_{i}}-1\right) \times 100 \%$, where $b_{i}$ is the estimated coefficient.
} 
agreements might also cause trade diversion.) Language is statistically and economically significant under both estimation procedures, and the estimates are remarkably close. ${ }^{25}$

In the regressions without fixed effects, I also control for two time-invariant country-specific characteristics typically included in gravity equations: Geographical areas and access to water. Despite these controls, there are still significant differences in the coefficients of all regressors depending on whether country-fixed effects are included or not. This reflects the fact that other country-specific characteristics play an important role, and that is why, throughout the paper, I focus exclusively on the regression outcomes that include country effects. ${ }^{26}$

Turning to the main focus of this paper, the effect of exchange rate variability, while small under both OLS and PML, is almost twice as high (in absolute value) using PML. In both cases, the coefficients are significantly different from zero. Equation (3) indicates that, absent endogeneity problems, the elasticity of (expected) trade with respect to $\delta_{i j}$ will be given by:

$$
\frac{\partial E\left(T_{i j t} \mid x_{i j t}\right)}{\partial \delta_{i j t}} \cdot \frac{\delta_{i j t}}{T_{i j t}}=\hat{\alpha}_{\delta} \frac{\delta_{i j t}}{1+\delta_{i j t}}
$$

where $\hat{\alpha}_{\delta}$ is the estimated coefficient on the regressor $\ln \left(1+\delta_{i j t}\right)$. The values for $\hat{\alpha}_{\delta}$ are -0.42 (s.e.= 0.08 ) and -0.86 (s.e. $=0.018)$, using OLS and PML, respectively. At the mean value of $\delta_{i j t}$ (which is approximately 0.05), OLS generates an elasticity of -0.02 , and PML an elasticity of -0.04 . To illustrate the economic significance (or insignificance) of these numbers, the OLS estimate implies that, as a result of an increase in $\delta_{i j t}$ from its mean value to one standard deviation above the mean

\footnotetext{
${ }^{25}$ Language, colonial ties, distance, and contiguity, are time-invariant pair specific characteristics — as opposed to country specific - and that is why the regressions with country-fixed effects still can identify their impact.

${ }^{26}$ It is worth pointing out that the coefficients on geographical and access to water differ quite significantly depending on the estimation technique. Access to water appears to be important for trade flows, according to PML regressions; the negative coefficients on the landlocked dummies can be interpreted as an indication that ocean transportation is significantly cheaper. In contrast, OLS results suggest that whether or not the exporter is landlocked does not influence trade flows, whereas a landlocked importer experiences lower trade; this asymmetry is hard to interpret. Regarding geographical areas, PML finds no significant effect, whereas OLS produces small negative elasticities.
} 
$(0.05+0.10=0.15)$, bilateral trade should decrease by 4 percent $(=-0.02 \times 2 \times 100 \%)$ PML, instead, predicts a decrease of 8 percent.

One typical question in the political debate is how much would be gained by completely eliminating exchange volatility, that is, reducing $\delta$ to zero. The answer, in this context, is given by:

$$
\frac{\hat{T}_{i j t}^{\delta=0}-\hat{T}_{i j t}^{\delta=\bar{\delta}}}{T_{i j t}^{\delta=\bar{\delta}}} 100 \%=\left[(1+\bar{\delta})^{-\alpha_{\delta}}-1\right] 100 \%,
$$

where $\hat{T}_{i j t}^{\delta=0}$ is the expected level of trade when there is no variability and $\hat{T}_{i j t}^{\delta=\bar{\delta}}$ is the corresponding value for $\delta=\bar{\delta}$, where $\bar{\delta}$ is the sample mean $(\approx 0.05)$. OLS predicts an annual increase in trade of 2.1 percent, whereas PML predicts an increase of 4.3 percent.

Table 2 shows the same regressions displayed in Table 1, but excluding the five main anchors. The reason for this exclusion is that the instruments developed in the next subsection are valid only for "client" countries (that is, anchor countries have to be dropped out), and, hence, to make the results comparable, I perform the regressions for the common sample. For the reasons discussed before, as well as for simplicity of exposition, throughout the rest of the paper, only the regression outcomes with country-fixed effects are reported. There are only two noticeable changes in the PML results: Excluding the main anchors leaves no role for language, whereas free-trade agreements, instead, show an even larger effect. In contrast, while the OLS estimated effect of language falls slightly, it remains statistically and economically significant. And, intriguingly, the puzzling negative effect of free-trade agreements generated by OLS and documented in Table 1, now becomes statistically insignificant. 
Table 2. Exchange Rate Volatility and Trade Excluding Anchor Countries

\begin{tabular}{|c|c|c|c|}
\hline & Sampl & ade $>0$ & Sample: All pairs \\
\hline & \multicolumn{3}{|c|}{ Dependent Variable: } \\
\hline & Log of trade & Trade & Trade \\
\hline & OLS-FE & PML-FE & PML-FE \\
\hline $\log$ of $(1+\delta)$ & $\begin{array}{c}-0.419^{* *} \\
(0.075)\end{array}$ & $\begin{array}{c}-0.825^{* *} \\
(0.169)\end{array}$ & $\begin{array}{c}-0.858^{* *} \\
(0.175)\end{array}$ \\
\hline Log of distance & $\begin{array}{c}-1.235^{* *} \\
(0.034)\end{array}$ & $\begin{array}{c}-0.824^{* *} \\
(0.061)\end{array}$ & $\begin{array}{c}-0.819^{* *} \\
(0.063)\end{array}$ \\
\hline Contiguity dummy & $\begin{array}{c}0.633^{* *} \\
(0.165)\end{array}$ & $\begin{array}{l}0.477^{*} \\
(0.187)\end{array}$ & $\begin{array}{c}0.499^{* *} \\
(0.191)\end{array}$ \\
\hline Common-language dummy & $\begin{array}{c}0.315^{* *} \\
(0.077)\end{array}$ & $\begin{array}{c}0.102 \\
(0.134)\end{array}$ & $\begin{array}{c}0.077 \\
(0.138)\end{array}$ \\
\hline Colonial-tie dummy & $\begin{array}{c}0.568^{* *} \\
(0.081)\end{array}$ & $\begin{array}{c}0.047 \\
(0.186)\end{array}$ & $\begin{array}{c}0.108 \\
(0.190)\end{array}$ \\
\hline Free-trade agreement dummy & $\begin{array}{l}-0.240 \\
(0.164)\end{array}$ & $\begin{array}{c}0.346^{* *} \\
(0.096)\end{array}$ & $\begin{array}{c}0.327^{* *} \\
(0.098)\end{array}$ \\
\hline Log of importer's GDP per capita & $\begin{array}{l}1.245^{* *} \\
(0.044)\end{array}$ & $\begin{array}{l}1.116^{* *} \\
(0.084)\end{array}$ & $\begin{array}{l}1.160^{* *} \\
(0.085)\end{array}$ \\
\hline Log of exporter's GDP per capita & $\begin{array}{l}1.444^{* *} \\
(0.044)\end{array}$ & $\begin{array}{l}1.176^{* *} \\
(0.087)\end{array}$ & $\begin{array}{l}1.225^{* *} \\
(0.089)\end{array}$ \\
\hline Log of importer's population & $\begin{array}{c}0.958^{* *} \\
(0.093)\end{array}$ & $\begin{array}{c}0.000 \\
(0.096)\end{array}$ & $\begin{array}{l}-0.010 \\
(0.081)\end{array}$ \\
\hline Log of exporter's population & $\begin{array}{l}1.093^{* *} \\
(0.092)\end{array}$ & $\begin{array}{c}0.048 \\
(0.101)\end{array}$ & $\begin{array}{c}0.044 \\
(0.087)\end{array}$ \\
\hline Year effects & Yes & Yes & Yes \\
\hline Country-fixed effects & Yes & Yes & Yes \\
\hline Observations & 139,348 & 139,348 & 228,242 \\
\hline R-squared & 0.67 & & \\
\hline
\end{tabular}

Note: The equations use annual data from 1970 to 1997 and allow for clustering of the error terms over time for country pairs. In OLS, the gravity equation is estimated in its $\log$ form. In PML, it is estimated in its multiplicative form. Results for the positivetrade sample and the whole sample are reported. Country effects refer to each member of the pair (not to a country pair). Clustered standard errors are in parentheses.

* significant at $5 \%$;* significant at $1 \%$

\subsection{Estimation}

In order to compute the propensity to share a common anchor, I first use logit regressions to calculate the probability that a potential client anchors its currency to one of the main reference currencies. The logit regressions are shown in Table A4 of the Appendix. I present a set of different specifications. 
The final computation makes use only of the regression presented in the last column which excludes statistically insignificant terms. The final IV results, however, are not quantitatively sensitive to their inclusion.

The probability of anchoring the currency to one of the main anchors increases when the client is closer to the anchor, and when they share a common colonial past. Also, the propensity to anchor the currency increases with the size of the anchor, among the five considered, where size is measured by GDP per capita and geographical area. The population of the anchor does not seem relevant, although it is likely that this insignificance is due to the high correlation between population and geographical area. Finally, the larger the difference in size (as gauged by per capita GDP and population) between anchor and client, the larger the propensity to anchor the currency. In other words, relative size seems to matter (although the difference in areas is virtually irrelevant). Note also that free-trade agreements, common language, contiguity, and access to water seem not to matter for the decision to anchor a country's currency.

From the estimated probabilities in the logit regressions, I use the formula in equation (6) to compute for each pair of countries the likelihood that they share a common anchor.

Table 3 presents the results of the IV estimation, using both the logarithmic and the multiplicative specifications of the gravity equation. Panel A displays the outcomes from the first-stage regression. The dependent variable in this stage is $\ln \left(1+\delta_{i j}\right)$, and the regression controls for all the variables in the second stage (including year- and country-fixed effects), together with the excluded IV: the common-anchor dummy. 
Table 3. Volatility and Trade. IV Estimation.

Propensity to Share a Common Anchor as IV

\begin{tabular}{ll}
\hline \hline Panel A. First Stage & \\
\hline & Dependent Variable: $\log (1+\delta)$ \\
\hline Probability of common-anchor & $-0.072^{* *}$ \\
& $(0.008)$ \\
Log of distance & $0.002^{* *}$ \\
Contiguity dummy & 0.000 \\
& 0.002 \\
Common-language dummy & $(0.001)$ \\
& $-0.001^{* *}$ \\
Colonial-tie dummy & $(0.001)$ \\
& $0.002^{* *}$ \\
Free-trade agreement dummy & $(0.001)$ \\
& $-0.012^{* *}$ \\
Log of importer's GDP per capita & $(0.001)$ \\
& $-0.031^{* *}$ \\
Log of exporter's GDP per capita & $(0.001)$ \\
& $-0.031^{* *}$ \\
Log of importer's population & $(0.001)$ \\
& -0.003 \\
Log of exporter's population & $(0.002)$ \\
& -0.003 \\
Year effects & $(0.002)$ \\
Country-fixed effects & Yes \\
F-test of excluded instruments; p-values & Yes \\
R-squared-first stage & 139,348 \\
\hline
\end{tabular}

The first column in Panel B displays the IV estimates of the impact of exchange rate variability on trade in the log-specification. The second and third columns show the corresponding effects in the multiplicative specification for the positive-trade subsample and the whole sample, respectively. 
Table 3 Continued

Propensity to Share a Common Anchor as IV

\begin{tabular}{lccc}
\hline \hline Panel B. Second Stage & \multicolumn{3}{c}{} \\
\hline \multicolumn{1}{c}{ Dependent Variable: } & $\log$ (trade) & Trade & Trade \\
\hline log of $(1+\delta)$ & Sample: Trade $>0$ & Sample: Trade $>0$ & Sample: All pairs \\
\hline & $(1.099$ & 4.012 & 2.329 \\
Log of distance & $-1.239^{* *}$ & $(2.381)$ & $(2.746)$ \\
Contiguity dummy & $(0.046)$ & $-0.835^{* *}$ & $-0.826^{* *}$ \\
& $0.629^{* *}$ & $0.485^{* *}$ & $(0.016)$ \\
Common-language dummy & $(0.168)$ & $(0.042)$ & $0.506^{* *}$ \\
& $0.318^{* *}$ & $0.113^{* *}$ & $0.041)$ \\
Colonial-tie dummy & $(0.079)$ & $(0.031)$ & $0.084^{* *}$ \\
& $0.570^{* *}$ & 0.043 & $0.030)$ \\
Free-trade agreement dummy & $(0.082)$ & $(0.039)$ & $(0.039)$ \\
& -0.222 & $0.384^{* *}$ & $0.351^{* *}$ \\
Log of importer's GDP per capita & $(0.215)$ & $(0.027)$ & $(0.027)$ \\
& $1.291^{* *}$ & $1.174^{* *}$ & $1.184^{* *}$ \\
Log of exporter's GDP per capita & $(0.395)$ & $(0.068)$ & $(0.053)$ \\
per capita & $1.490^{* *}$ & $1.234^{* *}$ & $1.249^{* *}$ \\
Log of importer's population & $(0.393)$ & $(0.071)$ & $(0.056)$ \\
& $0.963^{* *}$ & -0.158 & -0.086 \\
Log of exporter's population & $(0.097)$ & $(0.147)$ & $(0.115)$ \\
& $1.097^{* *}$ & -0.110 & -0.032 \\
Year effects & $(0.097)$ & $(0.146)$ & $(0.113)$ \\
Country-fixed effects & Yes & Yes & Yes \\
R-squared & Yes & Yes & Yes \\
\hline \hline
\end{tabular}

Note: The equations use annual data from 1970 to 1997. The gravity equation is estimated in log form in Panel B and in multiplicative form in Panel C. Results for the restricted sample (with positive trade) and the whole sample are reported. Country-fixed effects refer to each member of the pair (not to a country pair). Robust standard errors in parentheses. * significant at $5 \% ; * *$ significant at $1 \%$.

The instrument exhibits a strong explanatory power. The propensity variable passes the F-test of excluded instruments; the F- and p-values are reported in the bottom of Panel A, and are significantly above the cutoffs specified by Staiger and Stock (1997). To make a quantitative assessment one can ask what happens when the likelihood that two countries anchor their currencies to a common anchor changes from 1 to 0 . The answer is that exchange rate variability increases, on average, by 141 
percent. $^{27}$

The key message from Panel $\mathrm{B}$ in Table 3 is that exchange rate variability has no significant impact on trade. Accounting for endogeneity, hence, the negative effect found in the previous regressions disappears. The remaining variables have the expected signs, except for free-trade agreements, which, according to the logarithmic specification have a negative effect (albeit not significant), whereas according to the level specification, have a significantly positive effect. The magnitudes of the remaining coefficients also show substantial differences between the estimation in logs and in levels.

Table 4 summarizes the estimated elasticities of trade with respect to variability using the various procedures.

Table 4. Summary of Results. Estimated Elasticities

\begin{tabular}{c|c|c|c}
\hline \hline Estimation & Sample & Exogenous $\delta_{i j}$ & Endogenous $\delta_{i j}$ \\
\hline Log-form & Trade $>0$ & $-0.02^{s}$ & 0.05 \\
\hline PML & Trade $>0$ & $-0.04^{s}$ & 0.19 \\
PML & All Trade & $-0.04^{s}$ & 0.11 \\
\hline
\end{tabular}

Note: Elasticities are computed at the mean as $\frac{\partial E(T \mid x)}{\partial \delta} \cdot \frac{\bar{\delta}}{T}=\hat{\alpha}_{\delta} \frac{\bar{\delta}}{1+\delta}$

where $\hat{\alpha}_{\delta}$ is the estimated coefficient and $\bar{\delta}=0.05 ; s=$ significant.

Let us first compare the results under the assumption that $\delta_{i j}$ is exogenous. The PML elasticity is twice as large as that obtained by OLS in the log-linear form. Even in the absence of exogeneity, it is not clear a priori what the direction of the bias should be, as it depends on the complex relationships among all regressors and the distribution of the error terms. To better understand how the bias can

\footnotetext{
${ }^{27}$ Note, though, that this is an out-of-sample prediction, since the values of the propensities are strictly between 0 and 1 ; the purpose of this calculation is simply to illustrate that the partial relationship between the propensity and the exchange rate is not only statistically, but also quantitatively strong. The decrease in variability is computed at the average value $\bar{\delta}=0.05$ using the following approximation:

$$
\frac{(1+\delta)^{P=1}-(1+\delta)^{P=0}}{(1+\delta)^{P=0}} \cdot \frac{1+\bar{\delta}}{\bar{\delta}} 100 \%=[\exp (-0.072)-1] \frac{1+0.05}{0.05} 100 \%
$$

where -0.072 is the estimated coefficient in Table 3, Panel A.
} 
affect the estimate, consider the following simple bivariate model:

$$
y=x^{\gamma} \varepsilon
$$

where $i) \epsilon$ is log-normal, with $i i)$ conditional mean $E(\varepsilon \mid x)=1$, and $i i i)$ conditional variance $V(\varepsilon \mid x)=$ $\phi(x)$. Assuming $y>0$, the logarithmic formulation is given by:

$$
\ln y=\gamma \ln x+\ln \varepsilon
$$

and the OLS coefficient is given by $\hat{\gamma}=\gamma+\frac{\sum \ln x \cdot \ln \varepsilon}{\sum \ln ^{2} x}$. Since $E(\ln \varepsilon)=-\frac{1}{2} \ln [1+\phi(x)]$ by the lognormality assumption, the transformed error term depends on the regressors, and hence the OLS coefficient will be biased. One may conjecture that higher variability will tend to increase the variance of export flows. In this simple model, if $y$ is trade and $x$ is variability, this assumption implies that $\phi^{\prime}(x)>0$. And this causes OLS to be biased downwards. However, others may argue as well that if variability indeed harms trade links, higher variability will be associated with less trade, and, potentially, with lower variance, that is, $\phi^{\prime}(x)<0$. In this case, OLS estimates will be biased upwards, as is the case with the current estimates. This example illustrates that the bias is the result of numerous factors and, even in this extremely simplified model, its direction is hard to predict. In the more complex multivariate model presented in this paper, the task becomes impossible, as both the underlying distribution of errors and the interrelations among all variables, are unknown.

The previous discussion neglected the possibility that $\varepsilon$ could be correlated with $x$, for example, because of the omission of relevant characteristics, reverse causality, or measurement error. Adding these considerations complicates the analysis even more, as, for example, higher values of the error 
term (or omitted characteristics that tend to increase trade) might be associated with lower values of nominal exchange rate variability and higher variance of the error terms.

The main conclusion from this first column of results is that truncation does not seem to bias the results, at least when the relationship is estimated in levels.

The second column of Table 4 displays the elasticities generated by the log-IV and PML-IV approaches. The estimated elasticities, in all cases, are insignificantly different from zero, and the point estimates are positive.

The reason for this lack of effect can be rationalized by the fact that not only exchange rate fluctuations create uncertainty or risks, which tend to discourage risk-averse agents from trade across borders, but they might also create profitable opportunities. For example, if an exporting firm faces a randomly fluctuating price for its products, given the convexity of the profit function, the average profits with fluctuating price will be higher than the profits at the average price. ${ }^{28}$ Higher volatility might then lead to a larger volume of trade, depending, among other factors, on the demand elasticities. This positive effect will tend to counteract the negative effects usually cited in the discussion, leading to no significant effect on net. Also, the availability of forward contracts, currency options, and other derivatives might provide substantial hedging to reduce the uncertainty associated with exchange rate fluctuations.

The negative bias in estimators that do not correct for endogenous regressors vis-à-vis the PML-IV estimator can be attributed to the omission of characteristics that typically come along or are correlated with lower variability. Examples include lower and fewer regulatory barriers, higher investment in infrastructure for trade, coordination of monetary and fiscal policies, and compatibility in legal systems.

\footnotetext{
${ }^{28}$ See, for example, Varian (1992).
} 


\section{Concluding Remarks}

What is the quantitative impact of exchange rate variability on the volume of trade? This paper takes a long road to saying: Zero. However, the long road is not futile: In the quest for an answer, the process uncovers the problems associated with the techniques typically used in empirical applications of the gravity equation. Moreover, the methodological points raised in the paper and the proposed solution can be extended to other contexts where log-linearizations (or, more generally, non-linear transformations) coupled with heteroskedasticity and/or endogeneity threaten the consistency of simple estimators. Examples include production functions and Mincerian regressions for earnings.

I argue that partial corrections can be highly misleading, and that all biases should be tackled simultaneously. For that, I develop an IV PML approach that addresses the various potential biases highlighted in this paper.

The instrument I use relies on the fact that many countries find it useful to peg their currency to that of a large, and stable "anchor" country in order to reduce inflation. Hence, two countries that have chosen to peg officially or de facto to the same anchor will tend to experience low bilateral exchange rate variability. This observation motivates the use of the probability that two countries peg their currencies to the same anchor as an instrument for their bilateral exchange rate volatility. Importantly, the propensity to share a common anchor uses information on the relationship between the anchor country and each individual client country so that my instrument only captures reasons for pegging to the anchor country other than the desire to increase bilateral trade among the two clients.

The results show that the probability that a client anchors its currency to one of the main anchors increases when the client is closer to the anchor, and when they share a common colonial past. Also, the propensity to anchor the currency increases with the size of the anchor, among the five considered, 
where size is measured by GDP per capita and geographical area. The population of the anchor does not seem relevant, although it is likely that this insignificance is due to the high correlation between population and geographical area. Finally, the larger the difference in size (as gauged by per capita GDP and population) between anchor and client, the larger the propensity to anchor the currency. In other words, relative size seems to matter (although the difference in areas is virtually irrelevant).

The paper contributes to the international policy debate by showing that exchange rate variability does not affect trade flows. The elimination of exchange rate variability alone, hence, should not be expected to create any significant gain in trade in the aftermath of the new move towards stronger pegs. 


\section{References}

[1] Bacchetta P., and E. van Wincoop (2001). "Does Exchange Rate Stability Increase Trade and Welfare?" American Economic Review, 90:5, 1093-1109.

[2] Abrahms, R. (1980). "Actual and Potential Trade Flows with Flexible Exchange Rates," Federal Reserve Bank of Kansas City Working Paper No. 80-01.

[3] Alesina, A. and R. Barro (2002). "Currency Unions," Quarterly Journal of Economics, May, 409436.

[4] Alesina, A., R. Barro, and S. Tenreyro (2002). "Optimal Currency Areas," forthcoming, in M. Gertler and K. Rogoff (ed.), NBER Macroeconomics Annual. NBER Working Paper No. 9072.

[5] Anderson, J. (1979). "A Theoretical Foundation for the Gravity Equation," American Economic Review, 69, 106-116.

[6] Anderson, J. and E. van Wincoop (2003). "Gravity with Gravitas: A Solution to the Border Puzzle," forthcoming, American Economic Review.

[7] Barro, R. and S. Tenreyro (2001). "Closed and Open Economy Models with Marked-Up and Sticky Prices," NBER Working Paper 8043.

[8] Baxter, M. and A. Stockman (1989). "Business Cycles and Exchange Rate Regime: Some International Evidence," Journal of Monetary Economics, 23, 377-400.

[9] Bergstrand, J. (1985). "The Gravity Equation in International Trade: Some Microeconomic Foundations and Empirical Evidence," Review of Economics and Statistics, 69, 474-481.

[10] Broda, C., and J. Romalis (2003). "Identifying the relationship between Exchange Rate Volatility and Trade," mimeo Federal Reserve Bank of New York, November 2003.

[11] Central Intelligence Agency. World Factbook (2002). http://www.cia.gov/cia/publications/factbook/.

[12] Côté, A. (1994). "Exchange Rate Volatility and Trade: A Survey," Bank of Canada Working Paper 94-5.

[13] Davis, D. (1995). "Intra-industry Trade: A Hecksher-Ohlin-Ricardo Approach," Journal of International Economics, 39, 201-226. 
[14] Deardoff, A. (1998). "Determinants of Bilateral Trade: Does Gravity Work in a Neoclassical World?" in Jeffrey Frankel (ed.), The Regionalization of the World Economy. Chicago, IL: University of Chicago Press.

[15] De Grauwe, P. and F. Skudelny (2000). "The Impact of EMU on Trade Flows," Weltwirtschaftliches Archiv, 136, 381-400.

[16] Eaton, J. and S. Kortum (2001). "Technology, Geography and Trade," NBER Working Paper No. 6253.

[17] Eichengreen, B. and D. Irwing (1996). "The Role of History in Bilateral Trade Flows," NBER Working Paper No. 5565.

[18] Engel, C. and A. Rose (2000). "Currency Unions and International Integration," Journal of Monew, Credit and Banking, 136, 381-400.

[19] Feenstra, R. C., R. E. Lipsey, and H. P. Bowen (1997), "World Trade Flows, 1970-1992, with Production and Tariff Data," NBER Working Paper No. 5910.

[20] Feenstra, R., J. Markusen and A. Rose (1999). "Using the Gravity Equation to Differentiate Among Alternative Theories of Trade," http://www.econ.ucdavis.edu/ feenstra.

[21] Flood, R. and A. Rose (1995). "Fixing Exchange Rates: A Virtual Quest for Fundamentals," Journal of Monetary Economics.

[22] Frankel, J. (1997), Regional Trading Blocs in the World Economic System. Washington, DC: Institute for International Economics.

[23] Frankel, J. and S. Wei (1993). "Trade Blocs and Currency Blocs," NBER Working Paper No. 4335 .

[24] Frankel, J. and A. Rose (2002). "An Estimate of the Effect of Currency Unions on Trade and Growth, " Quarterly Journal of Economics.

[25] Gray, A. (2001). http://argray.fateback.com/dist/formula.html.

[26] Haveman, J. and D. Hummels (2001). "Alternative Hypotheses and the Volume of Trade: The Gravity Equation and the Extent of Specialization," mimeo Purdue University.

[27] Helpman, E. and P. Krugman (1985). Market Structure and Foreign Trade. Cambridge, MA: MIT Press.

[28] Hooper, P. and S. Kohlhagen (1978). "The Effect of Exchange Rate Uncertainty on the Prices and Volume of International Trade," Journal of International Economics, 8, 483-511. 
[29] International Financial Statistics, International Monetary Fund, Haver Analytics (2003).

[30] Reinhart, C. and K. Rogoff (2002). "The Modern History of Exchange Rate Arrangements: A Reinterpretation," NBER Working Paper No. 8963.

[31] Rose, A. (2000). "One Money One Market: Estimating the Effect of Common Currencies on Trade," Economic Policy, 15, 7-46.

[32] Rose, A. and E. van Wincoop (2000). "National Money as a Barrier to International Trade: The Real Case for Currency Union," American Economic Review, May, 386-90.

[33] Santos Silva, J. and S. Tenreyro (2003). "Gravity-Defying Trade," FRB Boston Series, Working Paper No. 03-01.

[34] Sekkat, K. (1997). "Exchange Rate Variability and EU Trade". Final Report to the Commission of the EU.

[35] Staiger, D. and J. Stock (1997). "Instrumental Variables Regression with Weak Instruments," Econometrica, 65, 557-586.

[36] Stock, J. and M. Yogo (2002). "Testing for Weak Instruments in Linear Regressions," NBER Technical Working Paper No. 284.

[37] Tenreyro, S. and R. Barro (2002). "Economic Effects of Currency Unions," FRB Boston Series, Working Paper No. 02-4 and NBER Working Paper No. 9435.

[38] Thursby, J. and M. Thursby (1987). "Bilateral Trade Flows, the Linder Hypothesis, and Exchange Risk," The Review of Economics and Statistics, 69, 488-495.

[39] Varian, H. (1992). Microeconomic Analysis, 3rd ed. New York, NY: W.W. Norton \& Company.

[40] Windmeijer, F. and J. Santos Silva (1997). "Endogeneity in Count Data Models: An Application to Demand for Health Care," Journal of Applied Econometrics, 12, 281-294.

[41] The World Bank. World Development Indicators CD-rom (2002). 


\section{Appendix A}

Table A1. Countries used in the study.

\begin{tabular}{|c|c|c|}
\hline \multicolumn{3}{|c|}{ Anchor Countries } \\
\hline France & South Africa & United States \\
\hline Germany & United Kingdom & \\
\hline & Client Countries & \\
\hline Albania & Ghana & New Zealand \\
\hline Algeria & Greece & Nicaragua \\
\hline Argentina & Guatemala & Niger \\
\hline Australia & Guinea & Nigeria \\
\hline Austria & Guyana & Norway \\
\hline Belgium-Luxembourg & Haiti & Pakistan \\
\hline Benin & Honduras & Panama \\
\hline Bolivia & Hong Kong & Paraguay \\
\hline Brazil & Hungary & Peru \\
\hline Bulgaria & Iceland & Philippines \\
\hline Burkina Faso & India & Poland \\
\hline Burundi & Indonesia & Portugal \\
\hline Cameroon & Iran & Romania \\
\hline Canada & Ireland & Russia \\
\hline Central African Rep. & Israel & Saudi Arabia \\
\hline Chad & Italy & Senegal \\
\hline Chile & Jamaica & Singapore \\
\hline China & Japan & Spain \\
\hline Colombia & Korea South & Sri Lanka \\
\hline Congo Dem. Rep. & Laos & Suriname \\
\hline Congo & Lebanon & Sweden \\
\hline Costa Rica & Madagascar & Switzerland \\
\hline Côte d'Ivoire & Malawi & Syria \\
\hline Cyprus & Malaysia & Tanzania \\
\hline Denmark & Mali & Thailand \\
\hline Dominican Republic & Malta & Togo \\
\hline Ecuador & Mauritania & Tunisia \\
\hline Egypt & Mauritius & Turkey \\
\hline El Salvador & Mexico & Uganda \\
\hline Equatorial Guinea & Mongolia & Uruguay \\
\hline Finland & Morocco & Venezuela \\
\hline Gabon & Nepal & Zambia \\
\hline Gambia & Netherlands & Zimbabwe \\
\hline
\end{tabular}

Note: trade data are aggregated for Belgium and Luxembourg, which are treated in the analysis as a unit. The values for the regressors are correspondingly adjusted. 
Table A2. Free-Trade Areas considered in the study, with Start and End Years.

\begin{tabular}{|c|c|c|c|}
\hline$\overline{\text { EU }}$ & & "Andean Com & unity \\
\hline Austria & 1995- & Bolivia & $1992-$ \\
\hline Belgium & $1967-$ & Colombia & $1992-$ \\
\hline Denmark & 1973- & Ecuador & 1992- \\
\hline Finland & 1995- & Venezuela & 1992- \\
\hline France & 1967- & & \\
\hline Germany & $1967-$ & Caricom & \\
\hline Greece & 1981- & Jamaica & $1968-$ \\
\hline Luxembourg & 1967- & Dominica & $1968-$ \\
\hline Ireland & $1973-$ & Guyana & $1995-$ \\
\hline Italy & $1967-$ & Suriname & 1995- \\
\hline Netherlands & $1967-$ & & \\
\hline Portugal & 1986- & Mercosur & \\
\hline Spain & 1986- & Argentina & 1991- \\
\hline Sweden & $1995-$ & Brazil & 1991- \\
\hline United Kingdom & $1973-$ & Paraguay & $1991-$ \\
\hline & & Uruguay & 1991- \\
\hline EFTA & & Bolivia & 1996- \\
\hline Austria & 1960-1995 & & \\
\hline Denmark & 1960-1972 & CER & \\
\hline Norway & $1960-$ & Australia & $1983-$ \\
\hline Portugal & $1960-1985$ & New Zealand & $1983-$ \\
\hline Sweden & 1960-1995 & & \\
\hline Switzerland & $1960-$ & West African & tates \\
\hline Iceland & $1970-$ & Benin & 1994- \\
\hline Finland & 1986-1995 & Burkina Faso & 1994- \\
\hline United Kingdom & $1960-1972$ & Côte d'Ivoire & $1994-$ \\
\hline & & Mali & 1994- \\
\hline EEA & & Niger & 1994- \\
\hline Iceland & 1994- & Senegal & $1994-$ \\
\hline Norway & 1994- & Togo & 1994- \\
\hline Austria & 1994- & & \\
\hline Finland & 1994- & Israel-US & \\
\hline Sweden & 1994- & Israel & 1985- \\
\hline $\mathrm{EU}$ & 1994- & United States & $1985-$ \\
\hline CEFTA & & Israel-EU & \\
\hline Hungary & $1992-$ & Israel & 1996- \\
\hline Poland & $1992-$ & $\mathrm{EU}$ & $1996-$ \\
\hline NAFTA & & Israel-EFTA & \\
\hline Canada & 1989- & Israel & 1993- \\
\hline Mexico & 1994- & EFTA & 1993- \\
\hline United States & $1989-$ & & \\
\hline & & Israel-Canade & \\
\hline Group of Three & & Israel & 1997- \\
\hline Colombia & $1995-$ & Canada & 1997- \\
\hline Mexico & $1995-$ & & \\
\hline Venezuela & $1995-$ & & \\
\hline
\end{tabular}


Table A3. Summary Statistics

\begin{tabular}{|c|c|c|c|c|}
\hline & \multicolumn{2}{|c|}{$\begin{array}{c}\text { Sample } \\
\text { With Anchors }\end{array}$} & \multicolumn{2}{|c|}{$\begin{array}{c}\text { Sample } \\
\text { Without Anchors }\end{array}$} \\
\hline & Mean & $\begin{array}{l}\text { Standard } \\
\text { Deviation }\end{array}$ & Mean & $\begin{array}{l}\text { Standard } \\
\text { Deviation }\end{array}$ \\
\hline$\delta$ & 0.052 & 0.106 & 0.054 & 0.109 \\
\hline $\log (1+\delta)$ & 0.048 & 0.078 & 0.049 & 0.080 \\
\hline Log of trade & 9.123 & 3.313 & 8.614 & 3.128 \\
\hline Trade & 315483.0 & 2541234.0 & 113122.1 & 843540.5 \\
\hline Log of distance & 8.733 & 0.762 & 8.744 & 0.758 \\
\hline Contiguity dummy & 0.026 & 0.160 & 0.025 & 0.157 \\
\hline Common-language dummy & 0.206 & 0.404 & 0.202 & 0.402 \\
\hline Colonial-tie dummy & 0.152 & 0.359 & 0.147 & 0.354 \\
\hline Free-trade agreement dummy & 0.018 & 0.134 & 0.014 & 0.116 \\
\hline Log of GDP per capita & 7.651 & 1.609 & 7.543 & 1.574 \\
\hline Log of population & 16.123 & 1.556 & 16.010 & 1.511 \\
\hline Log of geographical area & 12.273 & 2.116 & 12.192 & 2.124 \\
\hline Landlocked dummy & 0.170 & 0.376 & 0.180 & 0.384 \\
\hline Probability of common anchor & & & 0.038 & 0.048 \\
\hline Observations & 254,942 & & 228,242 & \\
\hline
\end{tabular}


Table A4. Propensity to Adopt the Currency of Main Anchors. Logit Estimation

\begin{tabular}{|c|c|c|c|c|c|c|c|}
\hline & $\overline{\text { Dependent }}$ & variable: & $\overline{c \text { common-ar }}$ & hor dums & & & \\
\hline Log distance & $\begin{array}{c}-0.509^{* *} \\
(0.176)\end{array}$ & $\begin{array}{c}-0.405^{* *} \\
(0.149)\end{array}$ & $\begin{array}{c}-0.621^{\text {** }} \\
(0.186)\end{array}$ & $\begin{array}{c}-0.607^{* *} \\
(0.200)\end{array}$ & $\begin{array}{c}-1.049^{* *} \\
(0.213)\end{array}$ & $\begin{array}{c}-1.179^{* *} \\
(0.243)\end{array}$ & $\begin{array}{c}-1.176^{* *} \\
(0.260)\end{array}$ \\
\hline Contiguity dummy & & $\begin{array}{c}0.589 \\
(0.637)\end{array}$ & $\begin{array}{l}-0.336 \\
(0.954)\end{array}$ & $\begin{array}{l}0.105 \\
(0.811)\end{array}$ & $\begin{array}{l}-0.498 \\
(0.842)\end{array}$ & $\begin{array}{l}-0.217 \\
(0.858)\end{array}$ & \\
\hline $\begin{array}{l}\text { Common-language } \\
\text { dummy }\end{array}$ & & & $\begin{array}{l}1.755^{* *} \\
(0.367)\end{array}$ & $\begin{array}{c}0.672 \\
(0.583)\end{array}$ & $\begin{array}{c}0.639 \\
(0.584)\end{array}$ & $\begin{array}{c}0.644 \\
(0.589)\end{array}$ & \\
\hline $\begin{array}{l}\text { Colonial-tie } \\
\text { dummy }\end{array}$ & & & & $\begin{array}{l}1.369^{*} \\
(0.546)\end{array}$ & $\begin{array}{l}1.614^{* *} \\
(0.575)\end{array}$ & $\begin{array}{l}1.508^{* *} \\
(0.578)\end{array}$ & $\begin{array}{l}2.032^{* *} \\
(0.328)\end{array}$ \\
\hline Free-trade agreement & & & & 0.109 & -0.161 & 0.136 & \\
\hline dummy & & & & $(0.539)$ & $(0.530)$ & $(0.564)$ & \\
\hline Log of anchor's & & & & & $1.913^{* *}$ & $1.698^{* *}$ & $1.777^{* *}$ \\
\hline GDP per capita & & & & & $(0.475)$ & $(0.468)$ & $(0.472)$ \\
\hline Log of anchor's & & & & & -0.898 & -1.055 & -1.149 \\
\hline GDP p.c. & & & & & $(0.610)$ & $(0.615)$ & $(0.678)$ \\
\hline Log anchor's population & & & & & $\begin{array}{c}0.819^{* *} \\
(0.231)\end{array}$ & $\begin{array}{c}0.904^{* *} \\
(0.255)\end{array}$ & $\begin{array}{c}0.929^{* *} \\
(0.266)\end{array}$ \\
\hline $\begin{array}{l}\text { Log ratio anchor's GDP p.c. } \\
\text { to client's GDP p.c. }\end{array}$ & & & & & & $\begin{array}{c}0.235 \\
(0.123)\end{array}$ & $\begin{array}{c}0.220 \\
(0.113)\end{array}$ \\
\hline Log ratio anchor's & & & & & & $0.216^{*}$ & $0.221^{*}$ \\
\hline population to client's & & & & & & $(0.109)$ & $(0.112)$ \\
\hline Log ratio of anchor's area & & & & & & -0.089 & -0.077 \\
\hline to client's area & & & & & & $(0.086)$ & $(0.081)$ \\
\hline Landlocked-client dummy & & & & & & $\begin{array}{l}-0.157 \\
(0.384)\end{array}$ & \\
\hline Observations & 13,926 & 13,926 & 13,926 & 13,926 & $13,926^{\prime \prime}$ & 13,136 & 13,136 \\
\hline Pseudo R-squared & 0.03 & 0.03 & 0.11 & 0.13 & 0.23 & 0.25 & 0.25 \\
\hline
\end{tabular}

Note: The sample consists of country-pairs that include the five candidate anchors: France, Germany, South Africa,United Kingdom, and United States. The equations are for annual data and allow for clustering over time for country pairs. Clustered standard errors in parentheses.

* significant at $10 \%$;* significant at $5 \%$; *** significant at $1 \%$. 


\section{Appendix B}

To frame the empirical estimation, I follow Barro and Tenreyro (2001)'s model of international trade. The baseline model consits of competitive firms that produce output using a varieties-type production function à la Spence (1976), Dixit and Stiglitz (1977). The output of firm $i$ is given by:

$$
Y_{i}=L_{i}^{1-\alpha} \cdot \sum_{j=1}^{N^{I}+N^{I I}} X_{j i}^{\alpha},
$$

where $L_{i}$ is firm $i$ 's employment of labor, $0<\alpha<1, X_{j i}$ is the amount of intermediate input of type $j$ used by firm $i$, and $N$ is the number of types of intermediates available. In the baseline model, there are two countries, where country $I$ produces the intermediates $j=1, \ldots, N^{I}$ and country $I I$ the intermediates $j=N^{I}+1, \ldots, N^{I}+N^{I I}{ }^{29}$ Intermediate inputs are differentiated goods and, to simplify the setting, there is no overlap in the range of goods produced by the two countries. A country that is larger in terms of number of products is assumed to be larger in the same proportion in terms of labor: $\frac{N^{I}}{L^{I}}=\frac{N^{I I}}{L^{I I}}$ and the ratios are normalized to 1 . Within each economy, labor markets are perfectly competitive; however, there is no migration across borders.

The shipping of an intermediate good across country borders entails transaction costs, which are assumed to feature an "iceberg" technology: for each unit of intermediate good shipped from country $I$ to country $I I$ or the reverse, $b$ units arrive, with $0<b<1$.

Each firm maximizes profit, taking as given the real wage rate, $W$, and the price, $p_{j}$, of each type of intermediate good. (The prices are all measured in units of final product.) The first-order conditions for the choices of intermediate inputs are:

$$
\begin{aligned}
\alpha L_{i}^{1-\alpha} X_{j i}^{\alpha-1} & =p_{j}, j=1, \ldots, N^{I}, \\
\alpha L_{i}^{1-\alpha} X_{j i}^{\alpha-1} & =\left(\frac{p_{j}}{b}\right), j=N^{I}+1, \ldots, N^{I}+N^{I I} .
\end{aligned}
$$

Every producer of final goods will use all $N^{I}+N^{I I}$ varieties of the intermediate inputs as long as all of the prices are finite and $0<b<1$.

Final output is a homogeneous good that can be used for consumption or to produce intermediate goods. To simplify matters, consumption goods are identical and their transportation entails no cost; hence, their prices are the same everywhere and are normalized to one.

Prices of intermediates depend on the extent of monopoly power: if there is only one potential producer in each sector, the constant-elasticity demand function implied by the Spence-Dixit-Stiglitz formulation determines the monopoly price of each intermediate good to be $1 / \alpha$. More generally, other forms of imperfect competition will lead to a marked-up price $p_{j}=m_{j}$, with $1<m_{j}<1 / \alpha$. Substitution into equation (2) determines the quantities of intermediates $j$ demanded by firm $i$ in country $I$ :

$$
\begin{aligned}
& X_{j i}=\left(\alpha / m^{I}\right)^{1 /(1-\alpha)} \cdot L_{i}, j=1, \ldots, N^{I} \\
& X_{j i}=\left[\left(\alpha / m^{I I}\right) \cdot(b)\right]^{1 /(1-\alpha)} \cdot L_{i}, j=N^{I}+1, \ldots, N^{I}+N^{I I} .
\end{aligned}
$$

From the perspective of incentives to use the intermediate inputs, markup pricing $\left(m^{I I}>1\right)$ and

\footnotetext{
${ }^{29}$ The model can be easily extended to include more than two countries.
} 
trading costs (the inverse of $b$ ) have similar and reinforcing effects. The value of these imported goods, gross of trading costs, is determined by multiplying the quantity of intermediates by $\mathrm{m}^{I I} / b$ :

$$
\alpha^{1 /(1-\alpha)}\left(\frac{b}{m^{I I}}\right)^{\alpha /(1-\alpha)} N^{I} N^{I I}
$$

An expression analogous to the second part of equation (3) determines the quantity of country I's intermediates used by final-goods producers in country $I I$. The corresponding value of the exports of intermediate goods from country $I$ to country $I I$ can be calculated, after multiplication by $m^{I} / b$, as

$$
\alpha^{1 /(1-\alpha)}\left(\frac{b}{m^{I}}\right)^{\alpha /(1-\alpha)} N^{I} N^{I I}
$$

The model predicts a standard gravity equation, where $N^{I}$ and $N^{I I}$ relate to the level of economic development, which in practice is proxied by per capita GDP's. Further correction by population (or labor force) is needed, as in the model all variables are normalized by size.

The model also predicts that higher trading costs, or lower $b$, reduce the overall volume of trade. Empirically, the parameter $b$ might relate to distance, tariff and non-tariff barriers, differences in culture, language, legal systems, and so on, that is, to all variables that can have an effect on transaction costs. In particular, $b$ might relate to costs of currency conversion (which tend to increase with exchange rate variability) and other costs associated to exchange rate volatility (e.g., planning accounting, and organizational costs). A standard specification for $b$ as a function of all trading cost is the multiplicative form: $b=\prod x_{k}^{a_{k} \cdot \frac{1-\alpha}{\alpha}}$, where $x_{k}$ are the "trade resistance" terms and $a_{k}$ are their corresponding elasticities. ${ }^{30}$

\footnotetext{
${ }^{30}$ One can also make the argument that higher transaction costs (in particular, high exchange rate variability) also affect the markups, as they allow for further market segmentation. Market segmentation could play in two directions: it might deter trade by the usual channels, or it may increase it by encouraging dumping practices.
} 